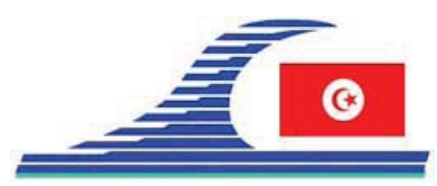

\author{
Conférence Méditerranéenne Côtière et Maritime \\ EDITION 1, HAMMAMET, TUNISIE (2009) \\ Coastal and Maritime Mediterranean Conference \\ Disponible en ligne - http://www.paralia.fr-Available online
}

\title{
Integrated in situ experimental monitoring and modelling of wave agitation in a marina
}

\section{Mario BERNERO ${ }^{1}$, Flavio CECCHI ${ }^{2}$, Enrico FOTI ${ }^{3}$, Eugenio PUGLIESE CARRATELLI ${ }^{4}$}

1. Hydraulic Research Wallingford, UK.

2. EMES, Rome, Italy.

3. Dept. Civil Environmental Engineering, University of Catania, and CUGRI, Italy. efoti@dica.unict.it

4. Dept. Civil Engineering, University of Salerno and CUGRI, Italy.epc@unisa.it

\begin{abstract}
:
In the last few years an enormous improvement has taken place in both numerical simulation and monitoring systems for harbour and marinas; the scale of action of such methods ranges from global weather and wave models to local hydrodynamic computation, and from wave satellite altimeters to local bottom mounted wave meters.

This report deals with a specific example where various data sources and modelling techniques were integrated to produce essential information about the behaviour of a harbour basin during storms.

Wave agitation in a newly built marina on the eastern Sicilian coast was simulated with state of the art software and monitored during the winter months with both bottom mounted and surface measuring devices, while external wave parameters were reconstructed from ECMWF data and cross checked with altimeter satellite measurements.
\end{abstract}

\section{Keywords:}

Coastal engineering - Wave monitoring - Wave data integration - Wave instrumentation - Maritime Hydraulics - Wave modelling

\section{The monitoring system}

The object of the monitoring programme was the outer basin of the Riposto marina (Fig. 1), located on the Eastern Sicilian coast, which was found to be affected by unusually high wave agitation. A long term monitoring program was therefore carried out during the 2008-2009 winter, under request of the builders, in order to ascertain the wave agitation behaviour during storms.

Two wave measuring system where deployed and run from September 2008 till March 2009. One of the systems, a TRITON-ADV, was bottom mounted at a depth of $8.5 \mathrm{~m}$, with an acquisition frequency of $2 \mathrm{~Hz}$, while on the quay edge a $4 \mathrm{~Hz}$ acoustic water height gauge (EMES DCU 1103) was installed.

$$
\text { DOI: } 10.5150 / \mathrm{cmcm} .2009 .067-1
$$




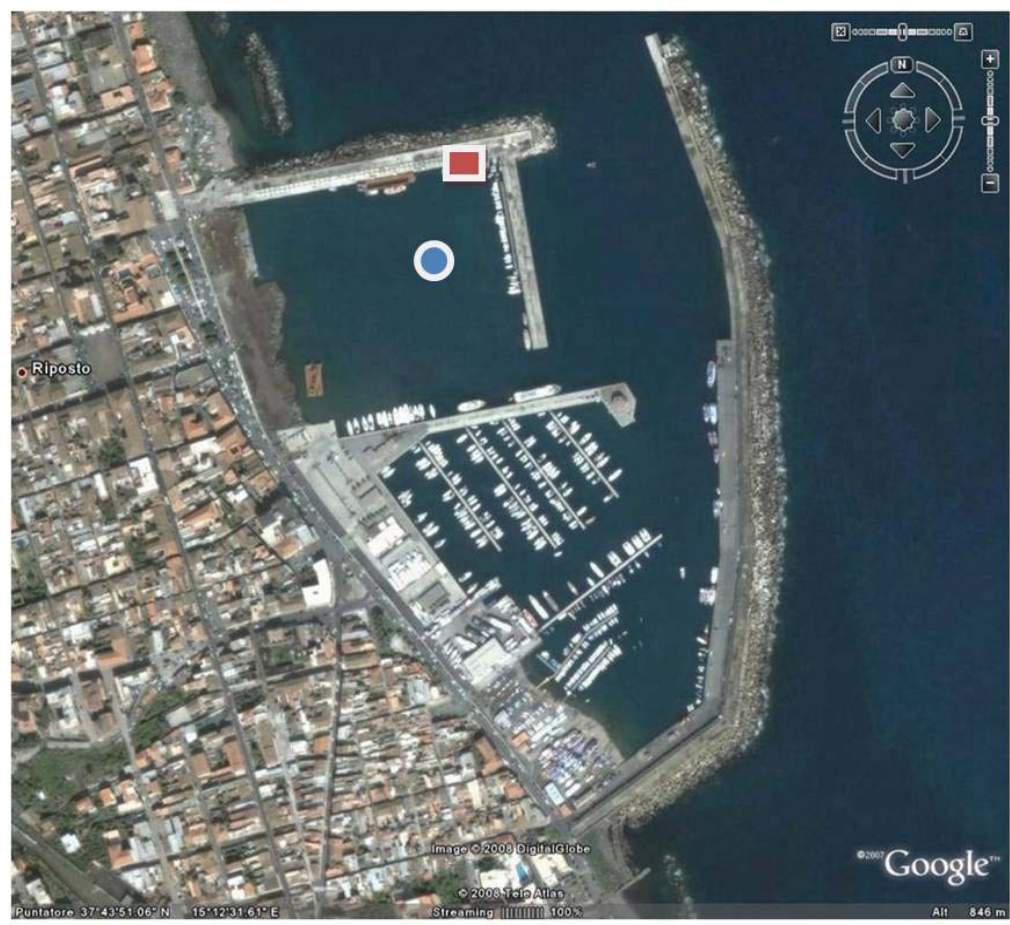

Acoustic Surface Gauge

Bottom Mounted Meter

Figure 1. Riposto marina, with wave gauge positions.

Both instruments had independent data logging capabilities and one of them (DCU 1103) also had a real time data connection through a GSM mode. Standard algorithms (Zero Crossing, FFT) were performed to extract wave parameters of interest. More than six months of data were collected, with some interruptions during long power breaks caused by very heavy storms.

\section{Offshore wave data reconstruction}

Since the main objective was to enquire upon the water waves reduction capability of the marina, it would have been desirable to have an offshore wave height record available. Such a record should have been provided by the Italian National Wavemeter Network buoy located off Catania, some 30 NM south along the coast; the buoy however was not working during the measurement campaign, so information about wave conditions could only be extracted from synthetic data or - occasionally - from satellite altimetry.

The wide diffusion of numerical weather forecast models has led to a now practically standard procedure based on the chain: Global Weather Model archive data - Local Area Model - Wave Generation and Propagation Model. Beside the ECMWF Mediterranean model, the most reliable publicly available system in the area is the NETTUNO model, implemented by Cavaleri (ISMAR-CNR, web site) and the Italian 
Air Force Meteorological Centre (CNMCA, web site), based on a $4.5 \mathrm{~km}$ Mediterranean WAM driven by COSMO-ME local area weather model.

Data from ECMWF were extracted for the four month period (October 2008 to December 2009) while NETTUNO data for November and December 2008 were provided by CNMCA. A comparison could thus be carried out between offshore sea state and internal agitation. Where possible, satellite altimeter data were used to crosscheck modelled data

\section{Wave agitation modelling}

A full understanding of the wave agitation within the basin necessarily requires an up to date modelling system. A mild slope equation solver (Pharos, by Deltares, in DINGEMANS, 1997) was therefore adapted to the harbour geometry and the wave reflection and diffraction patterns were thus analysed. Such calculations were performed for various offshore wave heights, directions and periods; figure 2 shows one example. A parametric connection could thus be established between offshore and internal wave heights.

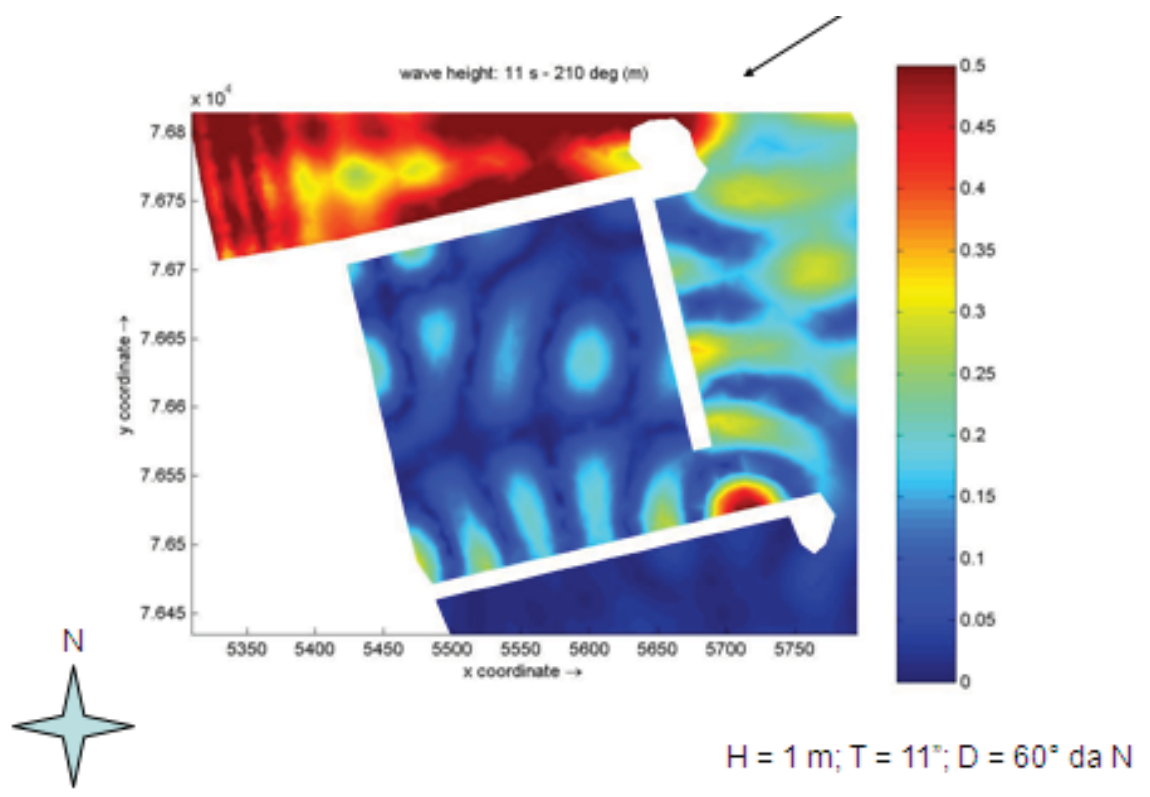

Figure 2. Riposto marina, water height in and around outer basin.

\section{Comparison}

Figure 3 shows the significant wave height as measured by the internal wave meter during the first few days of January 2009 and compared with model analysis. NETTUNO data were not available at the time, so this comparison was carried out with standard ECMWF products.

The Significant Wave Height (SWH) is seen to follow closely the offshore behaviour with a reduction coefficient (Basin SWH/Offshore SWH) varying between 0.05 and 0.1 , growing as the wave period goes up, thus reflecting the computed values. A full picture 
of the dependence of the coefficient on the various parameters will only be available when all the data are fully analysed.
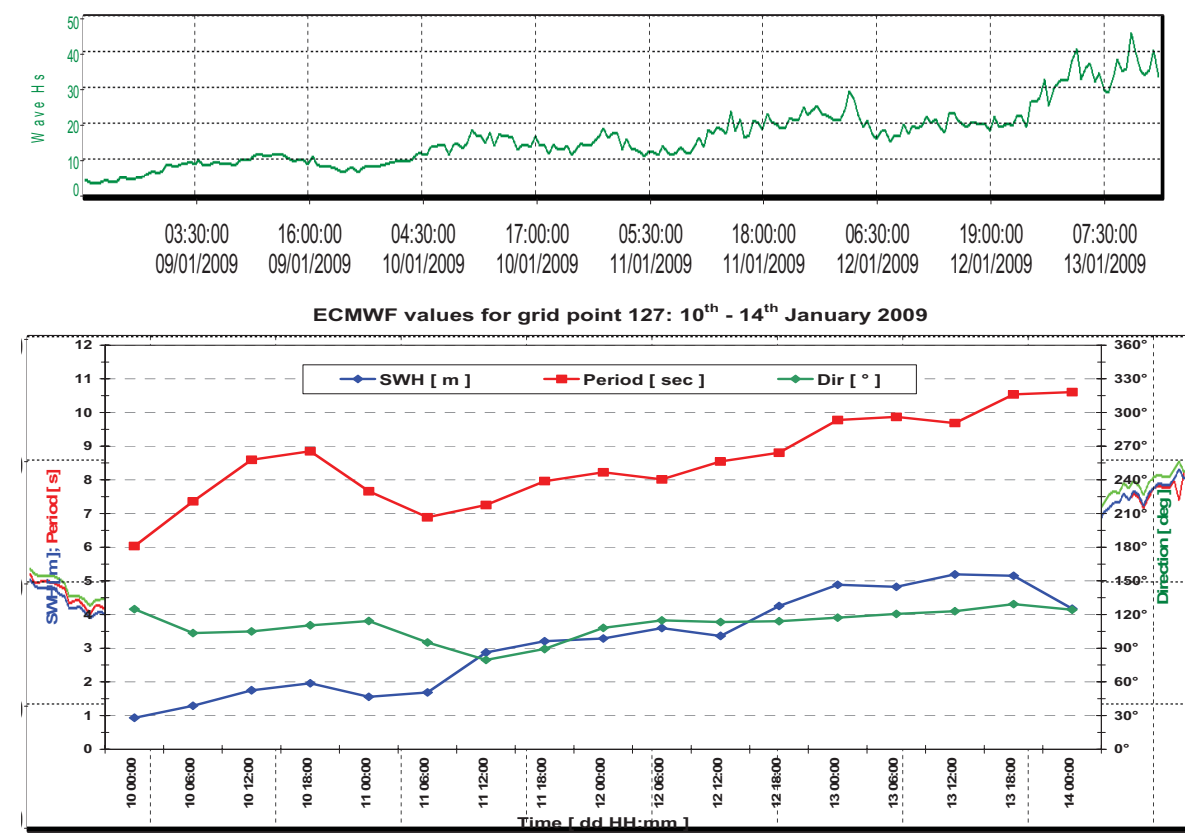

Figure 3. ECMWF (A) Analysis SWH, Period and Direction - (B) Recorded SWH at the sea bottom wave meter.

\section{Conclusion}

While none of the single steps of the monitoring programme was entirely new in itself, the application of different methods and technologies, over different time and space scales provides essential information. Even when offshore measured data are lacking, a careful integration of in situ data and up-to-date weather and wave simulation can provide a satisfactory evaluation of harbour effectiveness.

\section{Acknowledgements}

Italian Air Force Meteorological Centre (CNMCA) provided important data; Lt. Colonel Torrisi's precious help and advice was particularly appreciated.

The Authors are also grateful to the two companies "Mediterraneo Scarl" and "Walcom Italy" which, while pursuing their own commercial objectives, also provided a useful occasion to improve the understanding of marina harbour wave agitation problems.

\section{References}

CNMCA (web site). http://www.meteoam.it

DINGEMANS M.W. (1997). Water Wave Propagation Over Uneven Bottoms: Part 1. Linear Wave Propagation. World Scientific, Singapore.

ISMAR-CNR (web site). http://www.ismar.cnr.it 